\title{
Human immunodeficiency virus infection in breast cancer patients: The prevalence thereof and its effect on breast cancer characteristics at Dr. George Mukhari Academic Hospital Breast Clinic, Ga-Rankuwa, South Africa
}

\section{Authors:}

Nikoli van Zy ${ }^{1}$ (1)

Cornelia Minnéz

Dikeledi H. Mokone ${ }^{3}$ (D)

Affiliations:

${ }^{1}$ Department of Diagnostic

Radiology, Dr. George

Mukhari Academic Hospital,

South Africa

${ }^{2}$ Department of Diagnostic

Imaging, Dr. George Mukhari

Academic Hospital,

South Africa

${ }^{3}$ Department of Surgery, Dr. George Mukhari Academic Hospital, South Africa

Corresponding author:

Nikoli van Zyl,

vanzyInikoli@gmail.com

Dates:

Received: 04 May 2018

Accepted: 01 July 2018

Published: 30 Aug. 2018

How to cite this article:

Van Zyl N, Minné C,

Mokone DH. Human

immunodeficiency virus

infection in breast cancer patients: The prevalence thereof and its effect on breast cancer characteristics at Dr. George Mukhari Academic Hospital Breast Clinic, Ga-Rankuwa, South Africa S Afr J Rad. 2018; 22(2), a1361. https://doi. org/10.4102/sajr.v22i2.1361

Read online:
Background: Since the advent of highly active anti-retroviral therapy, improved immune functioning and prolonged survival of Human immunodeficiency virus (HIV)-positive patients has been accompanied by an increased incidence of non-AIDS-defining cancers (NADC). Breast cancer is the most prevalent NADC among HIV-positive women. However, data regarding the interaction between these two diagnoses remain limited.

Objectives: To determine the effect of HIV status on the presentation of breast cancer patients at Dr. George Mukhari Academic Hospital (DGMAH).

Methods: The age, gender, HIV status, CD4 count and tumour node metastases stage at presentation were recorded from the files of patients with histologically proven breast carcinoma, who had presented to the breast clinic at DGMAH from 01 January 2013 to 30 November 2017. Histological subtypes and molecular markers were retrieved from the National Health Laboratory Service. Prevalence of HIV among breast cancer patients was calculated. Cross-tabulations compared the variables between HIV-positive and HIV-negative groups. Statistical significance was assessed using Fisher's Exact Test.

Results: HIV status was determined in 129 breast cancer patients. Eighty (62.02\%) were HIVnegative and 49 (37.98\%) were HIV-positive. All patients were female. The mean age at presentation with breast cancer in the HIV-positive group was approximately 10 years younger, compared to the entire population and to the HIV-negative group $(p<0.0001)$. No further statistically significant associations were observed concerning HIV status and other variables.

Conclusion: HIV-positive women present with breast cancer at a significantly younger mean age. Breast cancer screening protocols may need to be adjusted accordingly in such patients.

\section{Introduction}

Human immunodeficiency virus (HIV) is a major burden in sub-Saharan Africa, with up to $70 \%$ of global HIV cases being reported in this region. ${ }^{1}$ In 2017, an estimated $12.6 \%$ (10.3\% in 2002) of the total South African population were infected with HIV. According to mid-year population estimates for 2017 released by Statistics South Africa, an estimated 17.98\% of South African adults (ages 15-49) were HIV-positive, and of these, 21.2\% were women aged 15-49.2,3

Recent studies have indicated that, since the advent of highly active anti-retroviral therapy (HAART), there has been an increase in the average life expectancy of HIV-positive patients from 49.2 years in 2003 to 60.5 years in $2011 .{ }^{4}$ Since the implementation of the National Anti-retroviral (ARV) Programme in 2005, the documented number of acquired immunodeficiency syndrome (AIDS)-related deaths has decreased by over 60\% between 2006 and $2017 .{ }^{3}$

Improvements in immune function because of HAART has also led to a decrease in the incidence of AIDS-defining malignancies, such as cervical cancer, non-Hodgkin's lymphoma and Kaposi's sarcoma. Conversely, the incidence of non-AIDS-defining cancers (NADC) has increased among HIV-positive patients. ${ }^{4,5}$ This is partially due to an increase in life expectancy among HIV-positive

Copyright: (C) 2018. The Authors. Licensee: AOSIS. This work is licensed under the Creative Commons Attribution License. 
patients; however, infection with human papillomavirus (HPV) and Hepatitis B and C, as well as high-risk behaviours such as smoking also play a causative role. ${ }^{5,6}$

Breast cancer is the most prevalent type of NADC among HIV-positive women. ${ }^{7}$ Worldwide, it is the most commonly diagnosed malignancy among women, regardless of immune status and socioeconomic standing. ${ }^{8,9}$ Breast cancer accounts for nearly a quarter of cancer diagnoses, and up to $14 \%$ of cancer-related deaths globally. ${ }^{10}$

Mid- to high-income regions generally exhibit a much higher incidence of breast cancer than low-income regions. Although sub-Saharan Africa presents one of the lowest incidences of breast cancer worldwide, there has been an alarming rise in recent years. This is postulated to be because of increased awareness and screening, as well as changes in reproductive patterns and lifestyle. ${ }^{7,9,10}$ Higher mortality rates in countries with historically lower incidence rates are thought to be because of late detection and limited access to treatment. ${ }^{7}$

Data regarding breast cancer on the African continent remains scarce because of poor record-keeping and data management. ${ }^{7,11}$ The National Cancer Registry in South Africa (SA) is merely a pathology-based registry, which underestimates the incidence of cancer and is not updated regularly. ${ }^{12}$

Three recently published literature reviews focussing on breast cancer (not including HIV) in Africa, sub-Saharan Africa and SA reported that patients presented at a younger age and at more advanced stage than patients from higherincome countries. ${ }^{7,11,13}$ The average age at presentation in women in West Africa, Kenya and Tanzania ranges from 35 to 45 years. ${ }^{11}$ In SA, the median age at presentation with breast cancer is $54-56$ years, ${ }^{14,15,16}$ versus 61 years in the United States of America (US). ${ }^{17}$

In SA, $50 \%-55 \%$ of patients were diagnosed with an advanced stage of breast cancer. ${ }^{6,11,14}$ In the rest of Africa, the presence of advanced-stage disease varied from 33\% in Morocco to $72.8 \%$ in Nigeria and $89.6 \%$ in Kenya. ${ }^{11}$ These figures are evidently much higher than the $8.4 \%$ observed in the US. ${ }^{17}$

Both local and international studies proved that patients living with HIV tend to present with breast cancer at a younger age relative to HIV-negative patients. ${ }^{6,18}$ No relation could be established between HIV and stage at diagnosis, tumour grade, tumour markers or molecular subtype. However, data was not conclusive, and further research was proposed. .,7,18,19 Literature reviews regarding the treatment of breast cancer in Africa, sub-Saharan Africa and abroad have reported that age and stage at presentation of breast cancer is not influenced by the CD4 count of HIV-positive patients. $7,11,18$

Several global studies have investigated the existence of a relationship between HIV and breast cancer, and whether
HIV is promotive or preventative to breast cancer.7,20,21 The proposed protective effect of HIV on breast cancer is explained by the binding of the main HIV coreceptor (CXCR4), which is expressed inter alia on hyperplastic and malignant breast duct cells. Although the exact mechanism remains unknown (it is suggested that activation of cell death pathways are involved), ${ }^{7}$ HIV CXCR4 tropism is associated with a lower risk of developing breast cancer. ${ }^{20,21}$ Conversely, it is also postulated that tumour progression via immune signalling, neo-angiogenesis and the metastatic spread of breast cancer may be induced by concomitant infection with HIV, which is attributed to 17 genes found in both diseases.?

If the hypothesis that HIV influences the presentation of breast cancer proves to be correct, a modified screening program for breast cancer could be formulated, which targets patients at a younger age if they are HIV-positive. Early diagnosis and treatment with improved outcomes are then possible.

\section{Methods}

This study is a descriptive study with retrospective enrolment and received ethical clearance from the Sefako Makgatho University Research Ethics Committee (SMUREC/ M/11/2016:PG).

The present study included the files of all patients who had presented to the breast clinic at Dr. George Mukhari Academic Hospital (DGMAH) from 01 January 2013 to 30 November 2017 with histologically proven breast carcinoma and a known HIV status. No HIV testing was performed for the purpose of the present study. The HIV statuses were obtained from patient files, the National Health Laboratory Service (NHLS) or by patient reporting.

The age, gender, HIV status, CD4 counts in cells per microliter $(\mu \mathrm{L})$ and tumour node metastases (TNM) stage at presentation were recorded. Histological subtypes and tumour molecular subtypes were retrieved from the NHLS and incorporated in the data.

Demographic details were descriptively summarised using frequency tables and graphs. Mean and standard deviation (minimum and maximum) was calculated for age at presentation. The prevalence of HIV in breast cancer patients was also calculated, and subsequent cross-tabulations were constructed between HIV status and age at presentation, stage of disease at presentation, histological subtypes and molecular subtypes.

We also compared the stages of presentation and CD4 count at presentation. For the purposes of the present study, patients were divided into four groups according to their CD4 count: CD4 counts of less than 200 cells $/ \mu \mathrm{L}$ (thus AIDS clinically), 201 cells $/ \mu \mathrm{L}-500$ cells $/ \mu \mathrm{L}, 501$ cells $/ \mu \mathrm{L}-1000$ cells $/ \mu \mathrm{L}$ and over 1000 cells $/ \mu \mathrm{L}$. The stage 
of breast cancer at presentation was also recorded for each group.

Fisher's Exact Test was performed for the aforementioned comparisons to assess statistical significance. All statistical analyses were performed using the SAS programme (SAS Institute Inc., Carey, NC, US, Release 9.4), running on Microsoft Windows.

\section{Results}

A total of 270 patients who had received a positive breast cancer diagnosis between 01 January 2013 and 30 November 2017 possessed files adequate for enrolment in the present study; 268 females and 2 males were observed. None of the male patients had a known HIV status and thus were not considered for further evaluation (Figure 1).

Of the 270 patients diagnosed with confirmed breast cancer, 129 (49\% of 270$)$ patients had a known HIV status. Of these, $80(62.02 \%$ of 129$)$ patients were HIV-negative and 49 (37.98\% of 129) were HIV-positive. All patients were females.

The mean age at presentation in HIV-negative patients was 53.18 years $( \pm 12.48)$, differing only slightly from that of the entire population, which was 54.56 years $( \pm 13.62)$ (Figure 2$)$. However, the patients in the HIV-positive group exhibited a much younger mean age at presentation of 44.86 years $( \pm 9.00)$ $(p<0.0001)$ - nearly 10 years younger than their HIV-negative peers (Figure 3).

Despite a significant difference in age at presentation, the stage at presentation did not vary significantly between the HIV-positive and HIV-negative groups ( $p=0.8912)$. A slightly higher percentage $(67.34 \%)$ of HIV-positive patients presented with advanced stages of breast cancer (stages $3 \mathrm{~B}$ and 4$)$ when compared to HIV-negative patients (63.75\%) (Figure 4).

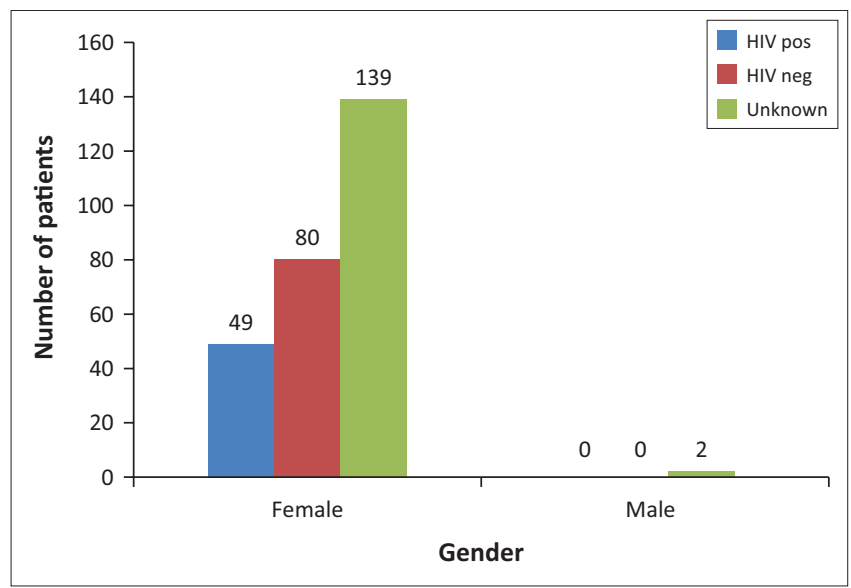

FIGURE 1: Depiction of human immunodeficiency virus status according to gender.

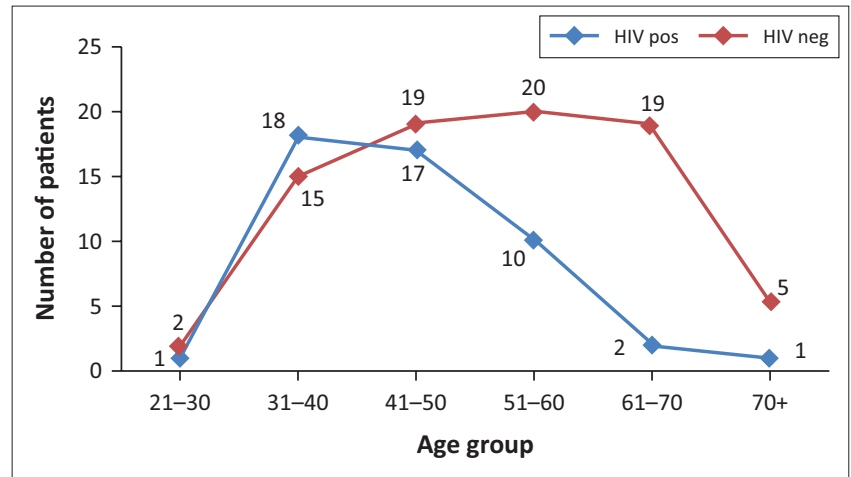

FIGURE 2: Summary of the age distribution of human immunodeficiency virus status in breast cancer patients.

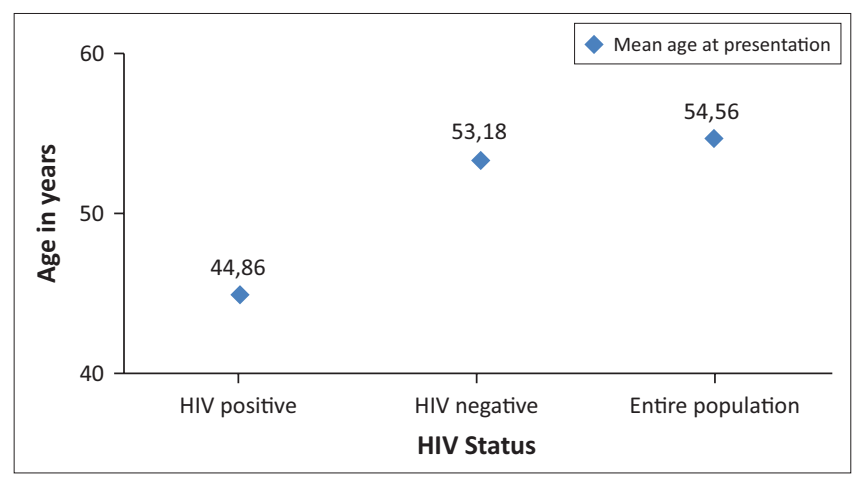

FIGURE 3: Mean age at presentation.

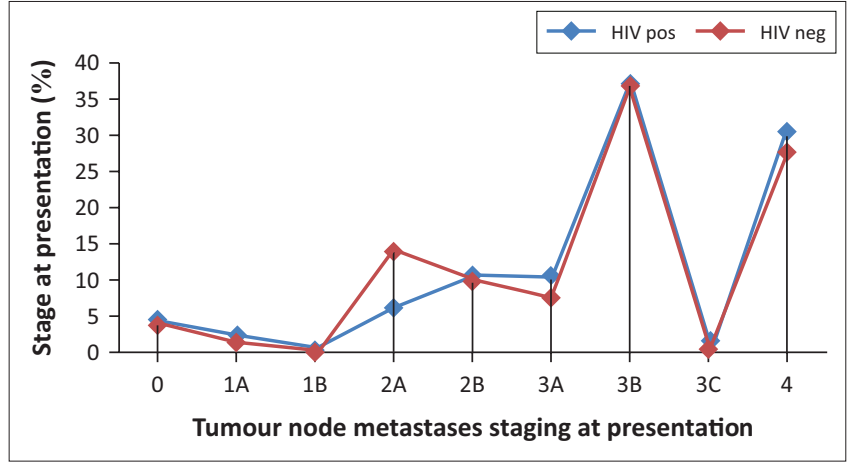

FIGURE 4: Summary of stage at presentation and human immunodeficiency virus status.

Analysis of CD4 counts among HIV-positive patients revealed that $10(25.64 \%)$ had a CD4 count of 0 cells $/ \mu \mathrm{L}-$ 200 cells $/ \mu \mathrm{L}, 16(41.03 \%)$ had a CD 4 count of 201 cells $/ \mu \mathrm{L}-$ 500 cells $/ \mu \mathrm{L}, 12(30.77 \%)$ had a CD 4 count of 501 cells $/ \mu \mathrm{L}-$ 1000 cells $/ \mu \mathrm{L}$ and one $(2.56 \%)$ had a CD4 count of over 1000 cells $/ \mu \mathrm{L}$ at presentation. CD4 counts were unavailable for $10(25.64 \%)$ patients.

Notably, among those with known CD4 counts, the percentage of patients who presented with advanced stages of breast cancer increased with declining CD4 counts (Figure 5). Overall, $90 \%$ of patients with a CD 4 count of 0 cells $/ \mu \mathrm{L}-200$ cells $/ \mu \mathrm{L}, 56 \%$ with 201 cells $/ \mu \mathrm{L}-500$ cells $/ \mu \mathrm{L}$ and $42 \%$ with 500 cells $/ \mu \mathrm{L}-1000$ cells $/ \mu \mathrm{L}$ exhibited advanced stages of breast cancer at the time of first staging, thereby demonstrating an inverse relationship. Only one HIV-positive patient 
exhibited a CD4 count over 1000 cells $/ \mu \mathrm{L}$, and presented with stage 4 breast cancer, which did not follow the trend demonstrated in other groups (Figure 5).

As expected, no significant difference $(p=0.9380)$ in the histological subtype of breast cancer was present upon

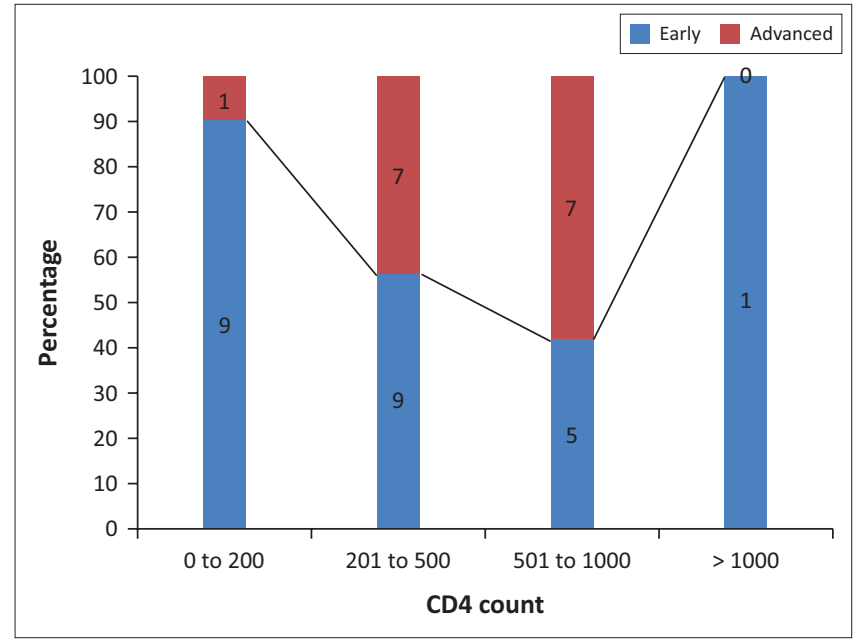

Key: RED $=$ Early: Stages 0-3A; BLUE $=$ Advanced: Stages 3B-4 Note: Frequency missing $=10(25.64 \%)$.

FIGURE 5: Ratio of patients presenting with early vs. advanced stage disease according to the CD4 count. comparing HIV-positive to HIV-negative patients (Figure 6). The histopathology report for one HIV-negative patient could not be traced, as the biopsy was performed in private practice and was not included in the file $(1.25 \%$ of 80$)$. The patient was referred to our institution with confirmed stage 4 breast carcinoma.

A number of specimens (indicated in the individual tables) were insufficient for the performance of some or all of the receptor status testing. The status of oestrogen, progesterone, human epidermal growth factor and KI67 protein receptors in the HIV-positive and HIVnegative patients are presented in Tables 1, 2, 3 and 4, respectively.

Molecular subtyping was possible in 96 of the patients with known HIV statuses. According to the criteria of the St Gallen 2013 Consensus Panel majority opinion, ${ }^{22} 19$ patients possessed triple-negative breast cancer, of which 7 of 38 (18.42\%) were HIV-positive and 12 of 58 (20.69\%) were HIVnegative $(p=1.00)$. Around $55.26 \%$ of the HIV-positive patients and $46.55 \%$ of the HIV-negative patients in this group had Luminal B type cancers ( $p=0.5315)$. HER2-enriched subtype was present in $13.16 \%$ of

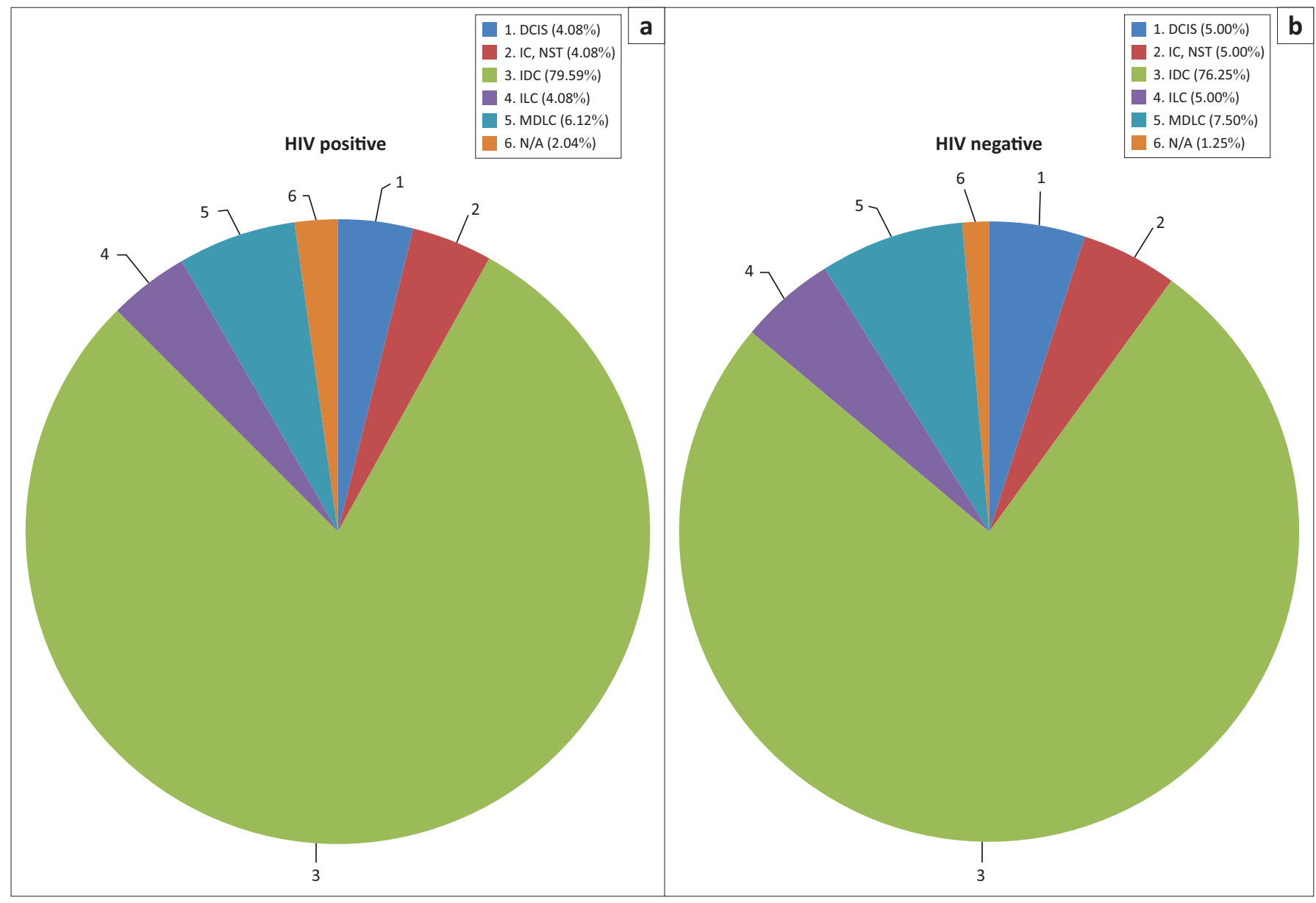

DCIS, Ductal carcinoma in situ; IC NST, infiltrating carcinoma of no specific type; IDC, intra-ductal carcinoma; ILC, intra-lobular carcinoma; MDLC, mixed ductal and lobular type; LPN, lymphoproliferative neoplasms; N/A, not available.

FIGURE 6: Percentages of different histological subtypes in relation to human immunodeficiency virus status: (a) HIV-positive and (b) HIV-negative. 
HIV-positive patients and $10.34 \%$ of the HIV-negative patients $(p=0.7483)$. None of these differences were statistically significant (Table 5).

TABLE 1: Oestrogen receptor status by human immunodeficiency virus status $\underline{(p=0.8336)}$

\begin{tabular}{|c|c|c|c|c|c|}
\hline \multirow[t]{3}{*}{ Oestrogen } & \multicolumn{4}{|c|}{ HIV } & \multirow[t]{3}{*}{ Total } \\
\hline & \multicolumn{2}{|c|}{ Neg } & \multicolumn{2}{|c|}{ Pos } & \\
\hline & $n$ & $\%$ & $n$ & $\%$ & \\
\hline Neg & 23 & 35.38 & 13 & 31.71 & 36 \\
\hline Pos & 42 & 64.62 & 28 & 68.29 & 70 \\
\hline Total & 65 & 100 & 41 & 100 & 106 \\
\hline
\end{tabular}

Note: Frequency missing $(n=23)$.

HIV, human immunodeficiency virus; Neg, negative; Pos, positive.

TABLE 2: Progesterone receptor status by human immunodeficiency virus status $(p=1.00)$.

\begin{tabular}{|c|c|c|c|c|c|}
\hline \multirow[t]{3}{*}{ Progesterone } & \multicolumn{4}{|c|}{ HIV } & \multirow[t]{3}{*}{ Total } \\
\hline & \multicolumn{2}{|c|}{ Neg } & \multicolumn{2}{|c|}{ Pos } & \\
\hline & $n$ & $\%$ & $n$ & $\%$ & \\
\hline Neg & 31 & 47.69 & 20 & 48.78 & 51 \\
\hline Pos & 34 & 52.31 & 21 & 51.22 & 55 \\
\hline Total & 65 & 100 & 41 & 100 & 106 \\
\hline
\end{tabular}

Note: Frequency missing $(n=23)$.

HIV, human immunodeficiency virus; Neg, negative; Pos, positive.

TABLE 3: Human epidermal growth factor receptor 2 status by human immunodeficiency virus status $(p=0.5157)$.

\begin{tabular}{|c|c|c|c|c|c|}
\hline \multirow[t]{3}{*}{ HER-2 } & \multicolumn{4}{|c|}{ HIV } & \multirow[t]{3}{*}{ Total } \\
\hline & \multicolumn{2}{|c|}{ Neg } & \multicolumn{2}{|c|}{ Pos } & \\
\hline & $n$ & $\%$ & $n$ & $\%$ & \\
\hline Neg & 46 & 71.88 & 26 & 65 & 72 \\
\hline Pos & 18 & 28.13 & 14 & 35 & 32 \\
\hline Total & 64 & 100 & 40 & 100 & 104 \\
\hline
\end{tabular}

Note: Frequency missing $(n=25)$.

HER-2, human epidermal growth factor receptor 2; Neg, negative; Pos, positive; HIV, human immunodeficiency virus.

TABLE 4: KI-67 protein receptor status by human immunodeficiency virus status $\underline{(p=0.0383)}$

\begin{tabular}{|c|c|c|c|c|c|c|}
\hline \multicolumn{2}{|c|}{ KI-67 } & \multicolumn{4}{|c|}{ HIV } & \multirow[t]{3}{*}{ Total } \\
\hline \multirow[t]{2}{*}{ Variable } & \multirow[t]{2}{*}{$p$} & \multicolumn{2}{|c|}{ Neg } & \multicolumn{2}{|c|}{ Pos } & \\
\hline & & $n$ & $\%$ & $n$ & $\%$ & \\
\hline Neg & $<15 \%$ & 32 & 53.33 & 12 & 30.77 & 44 \\
\hline Pos & $>15 \%$ & 28 & 46.67 & 27 & 69.23 & 55 \\
\hline Total & - & 60 & 100 & 39 & 100 & 99 \\
\hline
\end{tabular}

Note: Frequency missing $(n=30)$.

KI-67, KI-67 protein receptor; Neg, negative; Pos, positive; HIV, human immunodeficiency virus.

\section{Discussion}

Since breast cancer is the most prevalent type of NADC among HIV-positive women, ${ }^{7}$ the relationship between HIV and breast cancer has gained great interest over the past decade, with multiple studies being published on the topic both locally and internationally. ${ }^{5,6,7,13,14,18,19}$ This study attempted to either strengthen or question the available data.

Both local and international studies have investigated the interaction between HIV and breast cancer, though only proved that patients living with HIV tend to present with breast cancer at a younger age, compared to their HIVnegative counterparts. ${ }^{6,18}$ Cubasch et al. observed similarities in the age distribution of HIV in the general population and in HIV patients with breast cancer in Soweto. ${ }^{6}$ In line with previous publications, ${ }^{6,18,23}$ the most striking finding of our study concerns the difference in age at presentation with breast cancer, which varied based on patient HIV status: the mean age of breast cancer presentation in the HIV-positive group (44.86 \pm 9.00 years) was approximately 10 years younger than that of the HIV-negative group (53.18 \pm 12.48 years), and of the general population (54.56 \pm 13.62 years) $(p<0.0001)$ (Figure 3$)$. This raises the question whether HIVpositive patients should be screened for breast cancer at a younger age than the general population.

In the present study, the stage at presentation was not significantly influenced by HIV status, which correlates with available data from preceding studies. ${ }^{6,7,18,19}$ Studies performed in the US ${ }^{18,19}$ reported similar stages at presentation for HIV-positive and HIV-negative patients. The patients tended to present at earlier stages compared to that of subSaharan Africa. ${ }^{18}$ Cubasch et al. ${ }^{24}$ found that in excess of $50 \%$ of their breast cancer patients presented with an advanced stage of disease, either stage 3 or 4 , regardless of HIV status. It was then suggested that breast cancer may be detected at earlier stages in HIV-positive women if breast examination is included as standard of care at clinics providing primary health care to these women. Targeted education on breast self-examination may also be included. ${ }^{24}$

Age and stage at breast cancer presentation were found to be independent of the CD4 count of HIV-positive patients in Africa and sub-Saharan Africa., ${ }^{71}$ Moreover, international

TABLE 5: Molecular subtype by human immunodeficiency virus status.

\begin{tabular}{|c|c|c|c|c|c|c|c|}
\hline \multirow[t]{3}{*}{ Types } & \multirow[t]{3}{*}{ Subtypes } & \multicolumn{6}{|c|}{ HIV } \\
\hline & & \multicolumn{2}{|c|}{ Neg } & \multicolumn{2}{|c|}{ Pos } & \multicolumn{2}{|c|}{ Total } \\
\hline & & $n$ & $\%$ & $n$ & $\%$ & $n$ & $\%$ \\
\hline Luminal A & - & 13 & 22.41 & 5 & 13.17 & 18 & - \\
\hline \multirow[t]{3}{*}{ Luminal B } & - & 27 & 46.55 & 21 & 55.26 & 48 & - \\
\hline & Luminal B HER-2 neg & 15 & - & 11 & - & 26 & - \\
\hline & Luminal B HER-2 pos & 11 & - & 9 & - & 20 & - \\
\hline Luminal, HER2 N/A, KI- $67<14 \%$ & - & 0 & - & 0 & - & 0 & - \\
\hline HER2 enriched & - & 6 & 10.34 & 5 & 13.16 & 11 & -- \\
\hline Triple Neg & - & 12 & 20.69 & 7 & 18.42 & 19 & - \\
\hline Total & - & 58 & 100 & 38 & 100 & 96 & \\
\hline
\end{tabular}

HER-2, Human epidermal growth factor receptor 2; Neg, negative; Pos, positive; KI-67, KI-67 protein receptor; HIV, human immunodeficiency virus. 
studies also failed to demonstrate a relationship between these variables. ${ }^{18} \mathrm{We}$, however, determined that as the CD4 count of HIV-positive patients decreased, the likelihood of presenting with advanced stages of breast cancer increased. The single patient with a CD4 count over 1000 cells $/ \mu \mathrm{L}$ presented with stage 4 disease, which did not follow the trend demonstrated in the other groups (Figure 6). These results may be biased because of the small sample size and missing CD4 results for $10(25.64 \%)$ of the patients. The CD4 count at the time of breast cancer diagnosis may affect chemotherapy tolerance; however, there is a paucity of available data. ${ }^{11}$ This warrants further investigation.

Similarly, no statistically significant differences were demonstrated for histological and molecular subtypes. ${ }^{6,7,18,19}$ The most common histological subtype, regardless of HIV status, was by far IDC - as expected. The lymphoproliferative neoplasm was observed in only one HIV-positive patient. When comparing the molecular subtypes, one must consider that results for the receptor status testing were not available for all the samples. This may have led to bias in the results.

\section{Conclusion}

While HAART prolongs the survival of HIV-positive patients in South Africa, the incidence of NADCs is on the rise. An increasing number of patients - predominantly women - are facing both HIV and breast cancer. This study, albeit small, adds to the mounting evidence of breast cancer presenting earlier in women infected by HIV.

Because of the immense HIV burden in South Africa, it would be of great value to investigate its relationship with breast cancer on a national level. If the trends revealed in the present study (and others) are reproducible and generalisable to the South African population, it warrants a review of the management protocols for HIV-positive women.

Earlier screening for breast cancer in HIV-positive patients may decrease morbidity and mortality. Further research should be aimed at appropriate radiological screening methods for the younger population, while considering risk vs. benefit ratios, costs and the availability and diagnostic value of mammography, sonography and MRI. Furthermore, health care workers should be educated regarding the difference in breast cancer presentation in HIV-positive women, in order to increase their index of suspicion and ensure appropriate referral for further investigation and management. Patient knowledge and breast awareness should also be addressed by targeted education programmes.

\section{Study limitations}

A major drawback of this study is that the HIV statuses of $51 \%$ of the small cohort of patients with breast cancer were unknown, which precludes calculation and comparison of HIV prevalence. Incomplete or missing histological results further limited the study. The presence of additional breast cancer risk factors was unaccounted for.

\section{Acknowledgements}

The authors extend their gratitude to the nursing staff at the DGMAH Breast Clinic for their selfless and tireless assistance during the data collection process. They are also thankful to Prof. H.P. Schoeman (ClinStat) for his invaluable insights, who provided guidance during the writing of the research proposal and performed the statistical analysis.

\section{Competing interests}

The authors declare that they have no financial or personal relationships that may have inappropriately influenced them in writing this article.

\section{Authors' contributions}

N.v.Z. made substantial contribution to conception and design of the study. She wrote the research proposal; acquired, analysed and interpreted the data; drafted the manuscript and critically revised it for important intellectual content; and approved the final version to be published. C.M. made a substantial contribution to the conception and design of the study, assisted in drafting of the research proposal and in the analysis and interpretation of the data, critically revised the manuscript for important intellectual content and approved the final version to be published. D.H.M. made a substantial contribution to the conception and design of the study, provided guidance and support during acquisition of data and approved the final version to be published.

\section{References}

1. April MD, Wood R, Berkowitz BK, et al. The survival benefits of antiretroviral therapy in South Africa. J Infect Dis. 2014 Feb 15;209(4):491-499. https://doi. org/10.1093/infdis/jit584

2. Menezes CN. The need for an active role of the clinical radiologist in the management of the HIV-infected patients. S Afr J Radiol. 2017 Nov 14;21(2):1-2.

3. Statistics South Africa. Mid-year population estimates [homepage on the internet]. c2017 [cited 2018 Jan 27]; Statistical release P0302. Available from: www.statssa.gov.za

4. Bor J, Herbst AJ, Newell M-L, Bärnighausen T. Increases in adult life expectancy in rural South Africa: Valuing the scale-up of HIV treatment. Science. 2013 Feb 22;339(6122):961-965. https://doi.org/10.1126/science.1230413

5. Pinzone MR, Fiorica F, Di Rosa $M$, et al. Non-AIDS-defining cancers among HIVinfected people. Eur Rev Med Pharmacol Sci. 2012 Oct;16(10):1377-1388.

6. Cubasch $\mathrm{H}$, Joffe $M$, Hanisch R, et al. Breast cancer characteristics and HIV among 1,092 women in Soweto, South Africa. Breast Cancer Res Treat. 2013;140(1): 177-186. https://doi.org/10.1007/s10549-013-2606-y

7. Grover S, Martei YM, Puri P, et al. Breast cancer and HIV in sub-Saharan Africa: A complex relationship. J Glob Oncol. 2018 Jan 11;(4):1-11. https://doi. org/10.1200/JGO.2016.006585

8. Sengayi M, Babb C, Egger M, Urban MI. HIV testing and burden of HIV infection in black cancer patients in Johannesburg, South Africa: A cross-sectional study. BMC Cancer. 2015 Dec 18;15(1):144. https://doi.org/10.1186/s12885-015-1171-7

9. Kgaa M. Global burden of cancer in women. Int J Cancer. 2014;10:74-75.

10. Jemal A, Bray F, Center MM, Ferlay J, Ward E, Forman D. Global cancer statistics. CA Cancer J Clin. 2011 Mar;61(2):69-90. https://doi.org/10.3322/caac.20107

11. Vanderpuye V, Grover S, Hammad N, et al. An update on the management of breast cancer in Africa. Infect Agent Cancer. 2017 Dec 14;12(1):13. https://doi. org/10.1186/s13027-017-0124-y

12. South African National Department of Health. Breast cancer: Prevention and control policy. 2017[homepage on the internet] c2017 [cited 2018 May 07] Available from: http://www.health.gov.za/index.php/2014-03-17-09-09-38/policiesand-guidelines

13. Reddy P, Ebrahim S, Singh B, Ramklass S, Buccimazza I. Breast Cancer and HIV: A South African perspective and a critical review of the literature. S Afr J Surg. 2017;55(1):10-15. 
14. Langenhoven L, Barnardt P, Neugut Al, Jacobson JS. Phenotype and treatment of breast cancer in HIV-positive and -negative women in Cape Town, South Africa. J Glob Oncol. 2016 Oct 23;2(5):284-291. https://doi.org/10.1200/ JGO.2015.002451

15. Rayne S, Schnippel K, Fearnhead K, et al. Unravelling the South African breast cancer story: The relationship of patients, delay to diagnosis and stage with tumour biology in an urban setting. Eur J Cancer. 2018 Apr 1:92:S151. https://doi. org/10.1016/S0959-8049(18)30678-6

16. Moodley J, Cairncross L, Naiker T, Constant D. From symptom discovery to treatment - Women's pathways to breast cancer care: A cross-sectional study. BMC Cancer. 2018 Dec 21;18(1):312. https://doi.org/10.1186/s12885-018-4219-7

17. Grover S, Narasimhamurthy $M$, Bhatia $R$, et al. Comparing breast cance characteristics across sub-Saharan Africa and the United States. Eur J Cancer. 2018 Apr 1;92:S155. https://doi.org/10.1016/S0959-8049(18)30692-0

18. Presti $C$, Presti $C L$, Haslinger $M$, Wehner PB. Breast cancer in HIV-positive patients: A multi-institutional retrospective review. J Prev Med J Prev Med Health. 2017;1(2):1009.
19. Sarhan M, DePaz HA, Oluwole SFD. Breast cancer in women with human immunodeficiency virus infection: Pathological, clinical, and prognostic immunodeficiency virus infection: Pathological, clinical, and prognostic
implications. J Womens Health. 2010 Dec 27;19(12):2261-2266. https://doi.org/ 10.1089/jwh.2010.2026

20. Goedert JJ, Swenson LC, Napolitano LA, et al. Risk of breast cancer with CXCR4using HIV defined by V3 loop sequencing. J Acquir Immune Defic Syndr. 2015 Jan 1;68(1):30-35. https://doi.org/10.1097/QAl.0000000000000400

21. Hessol NA, Napolitano LA, Smith D, et al. HIV tropism and decreased risk of breast cancer. PLoS One. 2010 Dec 16;5(12):e14349.

22. Kos Z, Dabbs DJ. Biomarker assessment and molecular testing for prognostication in breast cancer. Histopathology. 2016 Jan;68(1):70-85. https://doi.org/10.1111/ his.12795

23. Aboulafia DM. Cancer screening in women living with HIV infection. Womens Health. 2017 Dec 27;13(3):68-79. https://doi.org/10.1177/1745505717731970

24. Cubasch $H$, Ruff $P$, Joffe $M$, et al. South African breast cancer and HIV outcomes study: Methods and baseline assessment. J Glob Oncol. 2017 Apr;3(2):114-124. https://doi.org/10.1200/JGO.2015.002675 